\title{
BMJ Open Risk of aortic dissection or aneurysm in patients with gallstone disease: a retrospective cohort study in Taiwan
}

\author{
Chien-Hua Chen, ${ }^{1,2,3}$ Cheng-Li Lin, ${ }^{4,5}$ Chia-Hung Kao (1) 6,7,8,9
}

\begin{abstract}
To cite: Chen C-H, Lin CL, Kao C-H. Risk of aortic dissection or aneurysm in patients with gallstone disease: a retrospective cohort study in Taiwan. BMJ Open 2021;11:e049316. doi:10.1136/ bmjopen-2021-049316
\end{abstract}

- Prepublication history and additional supplemental material for this paper are available online. To view these files, please visit the journal online (http://dx.doi.org/10.1136/ bmjopen-2021-049316).

Received 21 January 2021 Accepted 02 August 2021

Check for updates

(C) Author(s) (or their employer(s)) 2021. Re-use permitted under CC BY-NC. No commercial re-use. See rights and permissions. Published by BMJ.

For numbered affiliations see end of article.

Correspondence to

Dr Chia-Hung Kao;

d10040@mail.cmuh.org.tw

\begin{abstract}
Objective This nationwide population-based cohort study was to compare the risk of aortic dissection (AD) or aortic aneurysm (AN) between the subjects with and without gallstone disease (GD). We also compare the risk of $A D / A N$ between the patients with GD with and without cholecystectomy.

Setting This nationwide population-based cohort study. Participants We extracted the hospitalisation database from the National Health Insurance Research Database of Taiwan and identified a total of 343300 patients aged $\geq 20$ years with GD newly diagnosed between 2000 and 2010 as the study cohort, including 191111 with cholecystectomy and 152189 without cholecystectomy, respectively. We randomly selected those without $\mathrm{GD}$ as the control cohort, by 1:1 propensity score matching with the study cohort based on age, sex, comorbidities and year of the index date for GD diagnosis.
\end{abstract}

Results The incidence of AD/AN was $6.65 / 10000$ personyears for the GD cohort and 6.24/10 000 person-years for the non-GD cohort (adjusted HR (aHR) $=1.11,95 \%$ $\mathrm{Cl}=1.09$ to 1.13$)$, respectively $(\mathrm{p}<0.001)$. Furthermore, the incidence of $A D / A N$ in the patients with GD was 9.93/10 000 person-years for the non-cholecystectomy patients (aHR=1.24, 95\% $\mathrm{Cl}=1.22$ to 1.26$)$ and $4.63 / 10000$ person-years for the cholecystectomy patients (aHR=0.97, $95 \% \mathrm{Cl}=0.95$ to 0.99$)$, respectively $(\mathrm{p}<0.05)$.

Conclusions The GD cohort was associated with and greater risk of $\mathrm{AD} / \mathrm{AN}$ than the non-GD cohort, but the risk of $A D / A N$ in the patients with GD would decrease after cholecystectomy.

\section{INTRODUCTION}

Aortic aneurysm (AN) is per definition a localised increase of the diameter $>50 \%$, and the risk of dissection increases with incremental diameter to reach a mortality of $50 \%-80 \%$. $^{1}$ The lethal aortic dissection (AD) results from bleeding within the disrupted aortic wall. ${ }^{2}$ The reported prevalence of $\mathrm{AN}$ is lower in Asia than in Western countries. ${ }^{3-6}$ However, the incidence of AN in Taiwan has steadily increased from 6.46/100000 persons in 2005 to $8.25 / 100000$ persons in $2011 .^{7}$ Furthermore, with an average annual incidence of $5.6 / 100000$ persons, the incidence of $\mathrm{AD}$ in Taiwan has gradually increased between 2005

\section{Strengths and limitations of this study}

- The National Health Insurance programme is a mandatory and single-payer healthcare system with a coverage of almost every resident in Taiwan (99.6\%); therefore, the findings of this study with a 12-year-long follow-up provides the generalisability in Taiwan.

- Comparing the risk of aortic dissection or aneurysm between the gallstones patients with and without cholecystectomy, rather than between cholecystectomy and general population, mitigates the misclassification of asymptomatic gallstones into general population.

- This study is subject to the limited information on lifestyle and dietary habits.

- This observatory study cannot ascertain the protective mechanisms of cholecystectomy against the development of aortic dissection or aneurysm.

and $2011 .^{8}$ With an average annual mortality of 2/100 000 persons, the mortality of abdominal AD in Taiwan has significantly increased between 2005 and 2011. Without gender bias in the rupture and operative rates, the reported territory-wide operative mortality rates for intact and ruptured aneurysms were $10 \%(4 \%-24 \%)$ and $70 \% \quad(38 \%-100 \%)$, respectively. In general, the overall mortality was $17 \%$ for intact Abdominal Aortic Aneurysm (AAAs) and $78 \%$ for ruptured AAAs. ${ }^{4}$ The reported incidence and mortality of AD/ $\mathrm{AN}$ is actually expected to increase further due to increasing utilisation of CT and increasing prevalence of the elderly. $\mathrm{AD} / \mathrm{AN}$ will cast a heavy burden on medical expenditures and substantial disabilities on the patients' life. Therefore, it is important to identify the associated factors and to adopt feasible strategies for preventing this life-threatening disease.

The reported prevalence of gallstone disease (GD) in Taiwan is about $5 \%$ based on our former community study. ${ }^{9}$ With increasing prevalence of the elderly, sedentary lifestyle and metabolic disorders, GD is well known as one of the most common 
gastrointestinal tract disorders globally. Cholecystectomy for GD is clinically indicated for biliary complications and the reported annual complication rate of GD is only $1 \%-2 \%{ }^{10-12}$ There are several studies on the association between GD and cardiovascular disease (CVD) ${ }^{13-15}$ Cholesterol accumulation, oxidative stress, dysbiosis and genetic polymorphism for cholesterol metabolism have been shown to be the possible pathogenic mechanisms for the linkage between GD and CVD. ${ }^{16-20}$

The possible pathogenic mechanisms for $\mathrm{AD} / \mathrm{AN}$ is similar to that of CVD, such as inflammation, degradation of extracellular matrix and apoptosis of vascular smooth muscle cell. ${ }^{21-23}$ GD has been shown positively related to abdominopelvic atherosclerosis, ${ }^{24}$ and it can be found in 5\%-20\% of patients with an abdominal aortic aneurysm. ${ }^{25}$ In an old study, gallstones were detected in 42 of 865 patients $(4.9 \%)$ with abdominal AN.${ }^{26}$ However, the effect of cholecystectomy on $\mathrm{AD} / \mathrm{AN}$ has never been studied to date. In this study, we hypothesise that GD is associated with the development of AD/AN. Furthermore, we suppose that cholecystectomy will diminish the risk of $\mathrm{AD} / \mathrm{AN}$ if GD per se in an independent risk factor. This nationwide population-based cohort study uses the database of one hospitalisation database of the Taiwan National Health Insurance Research Database (NHIRD), to appraise the association between GD and the subsequent development of $\mathrm{AD} / \mathrm{AN}$. Furthermore, we also compare the risk (adjusted HR (aHR)) of AD/ AN between the patients with GD with and without cholecystectomy.

\section{METHODS}

\section{Cohort description}

Taiwan has launched the National Health Insurance (NHI) programme since 1 March 1995, and this singlepayer and compulsory medicare system has provided coverage more than $99.6 \%$ of the 23 million residents in Taiwan. ${ }^{27}$ All the information of NHI programme has been inputted into the NHIRD with the claim codes made based on 2001 International Classification of Diseases, ninth revision, Clinical Modification (ICD-9-CM).

\section{Recruitment criteria of the cohort}

We enrolled the patients aged $\geq 20$ years who had a new diagnosis of GD (ICD-9-CM 574) between 1 January 2000 and 31 December 2010 as the GD cohort. By 1:1 propensity score matching with the GD cohort based on index date for the diagnosis of GD, age, sex and comorbidities of hypertension, diabetes, hyperlipidaemia, coronary heart disease (CHD), heart failure, chronic obstructive pulmonary disease (COPD), peripheral artery occlusive disease (PAOD), chronic renal disease, stroke, cirrhosis and alcohol-related illness, we randomly selected the individuals without a history of GD or cholecystectomy as the control cohort. The main possible aetiologies of $\mathrm{AD} / \mathrm{AN}$ might include genetic disorders, syphilis, arteritis and trauma, but these aforementioned causes were relatively uncommon. In contrast, atherosclerosis is a common degenerative pathology and has been shown closely related to $\mathrm{AD} / \mathrm{AN}$ with a causal or epiphenomenal relationship. ${ }^{29}$ Therefore, hypertension, diabetes, hyperlipidaemia, CHD, heart failure, COPD, PAOD, chronic renal disease and stroke were selected as the explanatory variables. Since it remained debated for alcohol to be a risk factor of AN, we still listed cirrhosis and alcoholrelated illness as the explanatory variables. ${ }^{30}$ The index date for control patients was randomly appointed a month and day with the same index year of the matched GD cases. The patients with a history of AD or AN (ICD9-CM 441) or those without complete information on age or sex were excluded from the study. We only considered the major diagnosis (first three diagnoses) with $\mathrm{AD} / \mathrm{AN}$ (ICD-9-CM 441) for hospitalisation as the main outcome. We followed each individual from the enrolment to the event of $\mathrm{AD}$ or $\mathrm{AN}$, deceased or retraction from the NHI programme due to emigration, or up to 31 December 2011. We included the cause-specific and non-cause-specific deaths for analysis, but we censor the deaths when the causes of deaths were not identifiable. A history of hypertension, diabetes mellitus, hyperlipidaemia, CHD, heart failure, COPD, PAOD, chronic renal disease, stroke, cirrhosis, and alcohol-related illness after the baseline and before the endpoints were included as a time-dependent covariate for comorbidities.

\section{Statistical analysis}

The categorical distribution of age, sex and comorbidities were analysed by the $\chi^{2}$ test; nevertheless, the continuous variables of mean ages (SDs) and mean follow-up period (SDs) were analysed by the Student's t test. The Kaplan-Meier method was used to compare the survival and cumulative incidence of $\mathrm{AD} / \mathrm{AN}$ between the nonGD, GD with cholecystectomy and GD without cholecystectomy cohorts; nevertheless, we used the log-rank test to examine the differences between the cohorts. We estimated the incidence density rates of $\mathrm{AD} / \mathrm{AN}$ (expressed as dividing the event number of $\mathrm{AD} / \mathrm{AN}$ by the number of person-years for each variable) by stratification of age, sex and presence or absence of a comorbidity. The proportional hazard model assumption was also examined by using a test of scaled Schoenfeld residuals. In the model evaluating the risk of $\mathrm{AD} / \mathrm{AN}$ throughout the follow-up period, it revealed a significant relationship between Schoenfeld residuals for gallstones and follow-up time, suggesting the proportionality assumption was violated ( $p$ value $<0.001$ ). In the subsequent analyses, we stratified the follow-up duration to deal with the violation of proportional hazard assumption. The risk of $\mathrm{AD} /$ AN (expressed as aHRs and 95\% CIs) was analysed by univariable and multivariable Cox proportional hazard regression models. The multivariable Cox proportional hazard regression model included age, sex and comorbidities of hypertension, diabetes mellitus, hyperlipidaemia, CHD, heart failure, COPD, PAOD, chronic renal disease, stroke, cirrhosis and alcohol-related illness. The 
comorbidities after the baseline and before the endpoints were included as a time-dependent covariate in the Cox model. Death could be a competing risk for the outcome in this study. Therefore, we conducted the competing risk analysis for $\mathrm{AD} / \mathrm{AN}$ with death as a competing risk. However, the original National Health Research Institute (NHRI) database did not include mortality information. We used the discontinuity of NHI as a proxy of death for the mortality calculation. We calculated the correlation matrix of regression coefficients, and we find lower correlations among the regression coefficients for all covariates. The highest correlation in our data was 0.003 between the regression coefficients of cirrhosis and alcohol-related illness. We performed all statistical analyses with SAS V.9.4, and statistical significance was defined based on a two-tailed $\mathrm{p}<0.05$.

\section{Patient and public involvement}

Patients and members of the public were not involved with the experimental design or carrying out the study.
RESULTS

Table 1 presents the baseline characteristics of the GD and the non-GD cohort. With comparable matching for age, sex and each comorbidity, the study consisted of 343300 individuals in each cohort, respectively. The mean age was $60.3 \pm 16.8$ year for the GD cohorts and $60.6 \pm 16.8$ years for the non-GD cohort, respectively. With comparable gender distribution between women $(50.7 \%)$ and men $(49.3 \%)$, about $44.6 \%$ of the patients with GD were older than 65 years. The most common comorbidities in the GD cohort included hypertension (31.6\%), followed by diabetes (20.5\%), CHD (12.7\%) and stroke (11.3) in the order of the frequency. Among the 343300 patients with GD, cholecystectomy was performed in 191111 patients and no history of cholecystectomy was observed in the other 152189 patients. The rate of ageing population (aged $\geq 65$ years) was relatively greater in the noncholecystectomy cohort, but women was more prevalent in the cholecystectomy cohort.

Table 1 Distribution of age, gender and comorbidity between gallstones and comparison cohort

Gallstones

\begin{tabular}{lll}
\hline & $\begin{array}{l}\text { Without } \\
\text { cholecystectomy } \\
\mathrm{N}=343300\end{array}$ & $\begin{array}{l}\mathrm{N}=152189 \\
\mathrm{n}\end{array} \frac{\mathrm{n}}{\mathrm{n}} \%$
\end{tabular}

\begin{tabular}{|c|c|c|c|c|c|c|c|c|c|}
\hline \multicolumn{10}{|l|}{ Sex } \\
\hline Female & 173053 & 50.4 & 69832 & 45.9 & 103221 & 54.0 & 173917 & 50.7 & 0.01 \\
\hline Male & 170247 & 49.6 & 82357 & 54.1 & 87890 & 46.0 & 169383 & 49.3 & 0.01 \\
\hline
\end{tabular}

Age, years

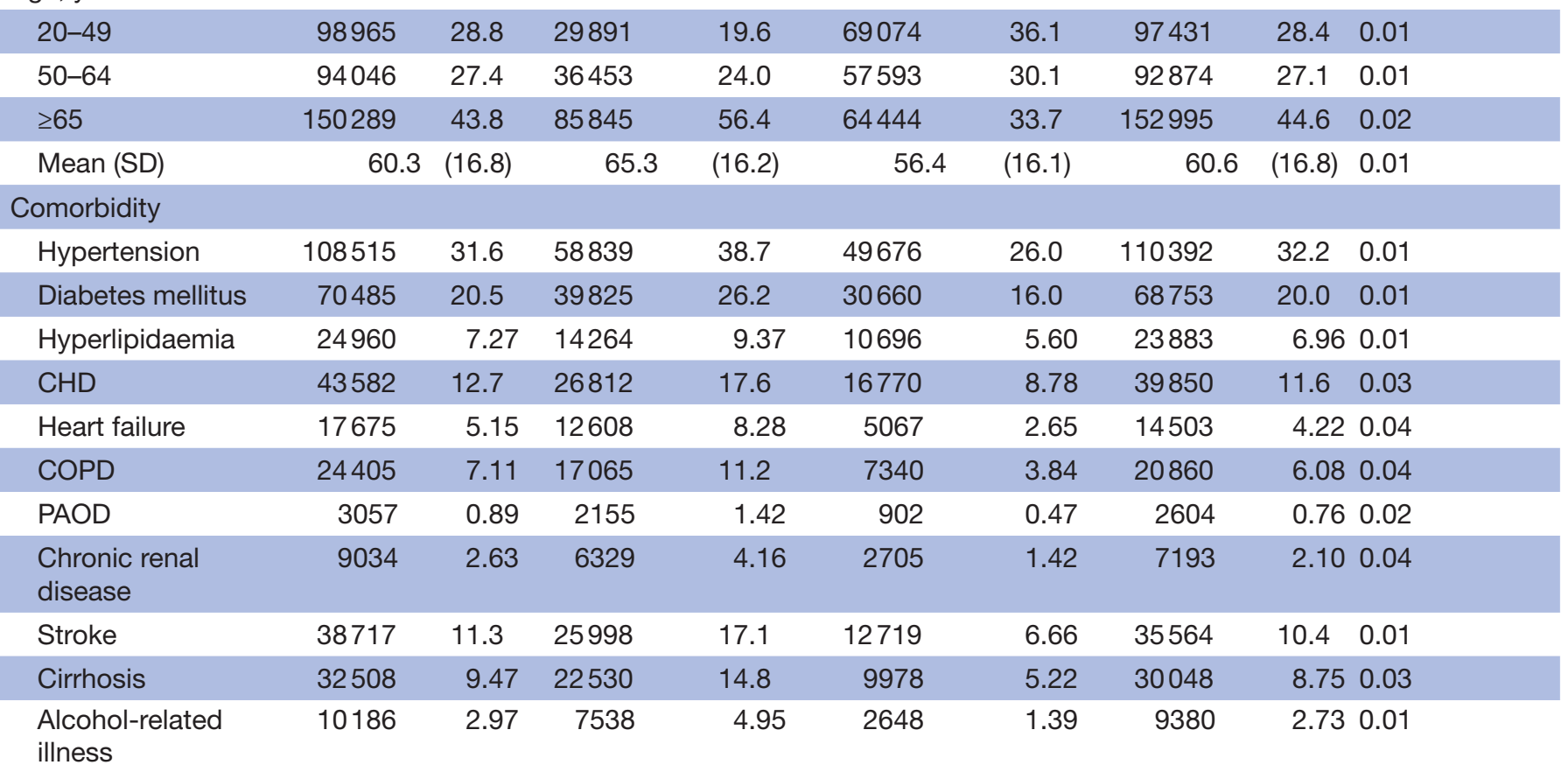

${ }^{*}$ A standardised mean difference of $\leq 0.10$ indicates a negligible difference between the total stroke versus comparison cohorts. $\mathrm{CHD}$, coronary heart disease; COPD, chronic obstructive pulmonary disease; PAOD, peripheral artery occlusive disease. 
Open access

Table 2 Incidence and HR of aortic dissection or aneurysm for associated-risk factors

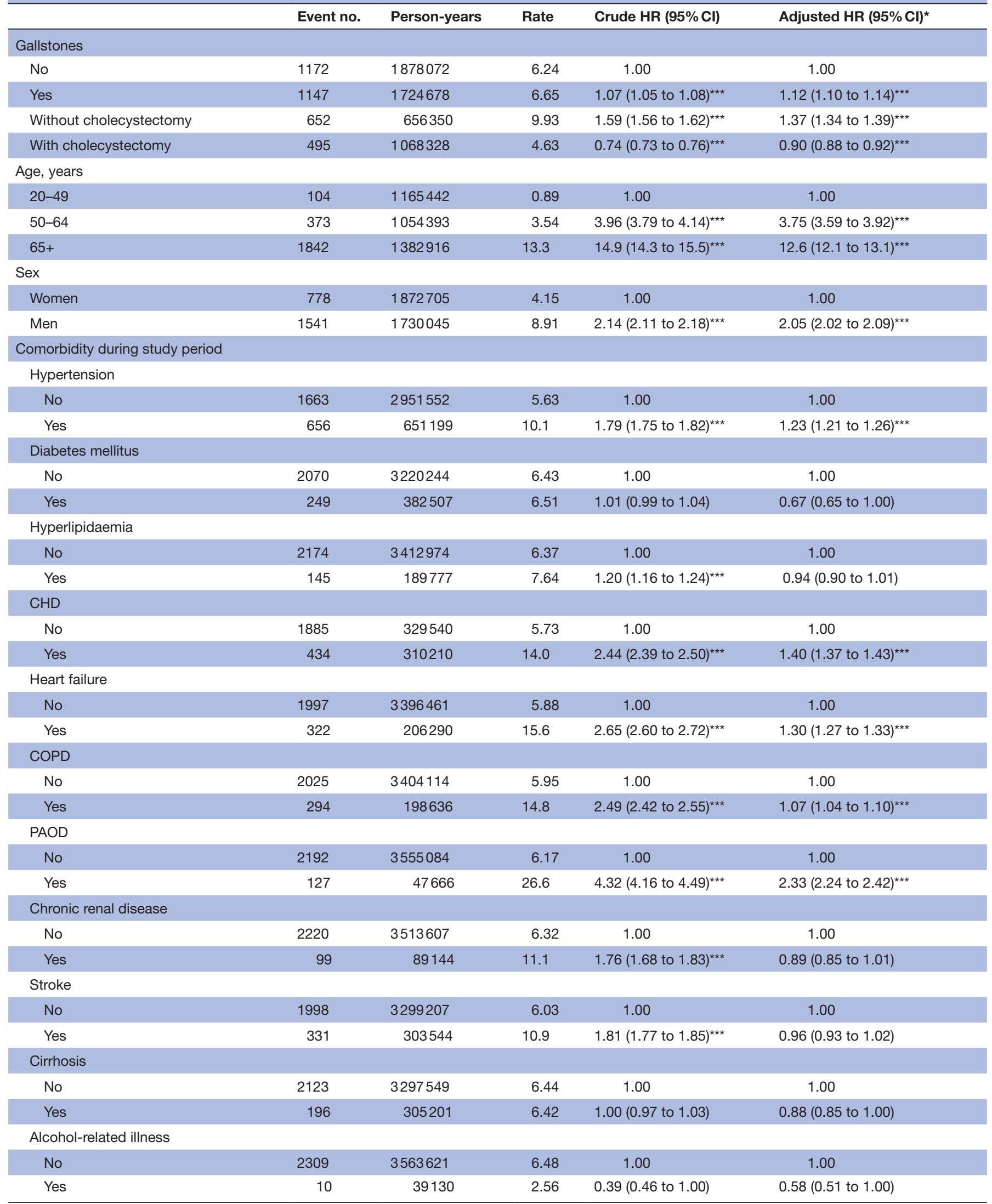

${ }^{* \star *} \mathrm{p}<0.001$

*Model was adjusted for age, sex and comorbidities of hypertension, diabetes mellitus, hyperlipidaemia, CHD, heart failure, COPD, PAOD, chronic renal disease, stroke, cirrhosis and alcohol-related illness.

CHD, coronary heart disease; COPD, chronic obstructive pulmonary disease; ; PAOD, peripheral artery occlusive disease; Rate, per 10000 person-years;. 


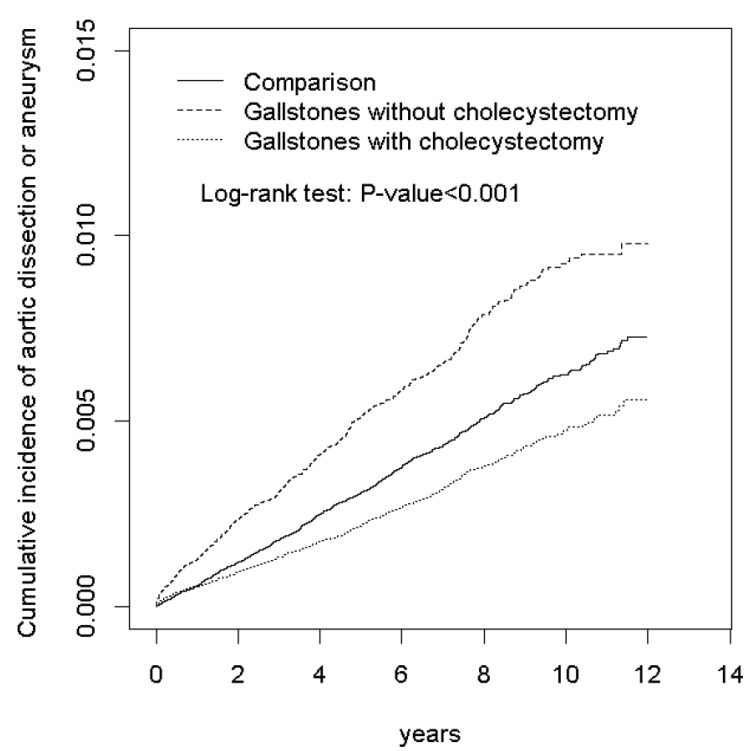

Figure 1 Cumulative incidence of aortic dissection or aneurysm compared among gallstones patients with cholecystectomy or without cholecystectomy, and nongallstones subjects.

Table 2 presents the incidence and $\mathrm{HR}$ of $\mathrm{AD} / \mathrm{AN}$ for associated-risk factors. GD $(\mathrm{aHR}=1.12,95 \% \mathrm{CI}=1.10$ to $1.14, \mathrm{p}<0.001)$, aged $50-64$ years $(\mathrm{aHR}=3.75,95 \% \mathrm{CI}=3.59$ to $3.92, \mathrm{p}<0.001)$ or $\geq 65$ years $(\mathrm{aHR}=12.6,95 \% \mathrm{CI}=12.1$ to $10.0, \mathrm{p}<0.001)$, men $(\mathrm{aHR}=2.05,95 \% \mathrm{CI}=2.02$ to 2.09, $\mathrm{p}<0.001)$, hypertension $(\mathrm{aHR}=1.23,95 \% \mathrm{CI}=1.21$ to $1.26, \mathrm{p}<0.001)$, CHD $(\mathrm{aHR}=1.40,95 \% \mathrm{CI}=1.37$ to 1.43, $\mathrm{p}<0.001)$, heart failure $(\mathrm{aHR}=1.30,95 \% \mathrm{CI}=1.27$ to 1.33, $\mathrm{p}<0.001)$, COPD $(\mathrm{aHR}=1.07,95 \% \mathrm{CI}=1.04$ to 1.10 , $\mathrm{p}<0.001)$ and PAOD $(\mathrm{aHR}=2.33,95 \% \mathrm{CI}=2.24$ to 2.42 , $\mathrm{p}<0.001)$ were associated with $\mathrm{AD} / \mathrm{AR}$ in multivariable Cox proportional hazard regression mode. However, it was noted that cholecystectomy $(\mathrm{aHR}=0.90,95 \% \mathrm{CI}=0.88$ to $0.92, \mathrm{p}<0.001$ ) were inversely associated with $\mathrm{AD} / \mathrm{AN}$ in our study.

Figure 1 shows the cumulative incidence of $\mathrm{AD} / \mathrm{AN}$ was greatest for the GD cohort without cholecystectomy, followed by the non-GD cohort and then the GD cohort with cholecystectomy (log-rank test $\mathrm{p}<0.001)$.

With non-GD group as the reference, table 3 presents the incidence and $\mathrm{HR}$ of $\mathrm{AD} / \mathrm{AN}$ compared between patients with and without gallstones based on the stratification of age, gender and comorbidity. The risk of $\mathrm{AD} / \mathrm{AN}$ for the GD cohort was greater than that for the non-GD cohort in each stratification of age (except for aged 50-64 group), sex, the absence of a comorbidity and follow-up period. Furthermore, the risk of $\mathrm{AD} / \mathrm{AN}$ for the GD cohort without cholecystectomy was persistently greater than that for the non-GD cohort in each stratification (except for the presence of a comorbidity). However, compared with the non-GD cohort, the risk of $\mathrm{AD} / \mathrm{AN}$ was lower for the GD cohort with cholecystectomy in those aged $50-64$ years $(\mathrm{aHR}=0.85,95 \% \mathrm{CI}=0.81$ to 0.88 , $\mathrm{p}<0.001)$, and aged $\geq 65$ years $(\mathrm{aHR}=0.92,95 \% \mathrm{CI}=0.89$ to $0.95, \mathrm{p}<0.001)$, women $(\mathrm{aHR}=0.86,95 \% \mathrm{CI}=0.83$ to
0.89, $\mathrm{p}<0.001)$, those without comorbidity $(\mathrm{aHR}=0.90$, $95 \% \mathrm{CI}=0.88$ to $0.93, \mathrm{p}<0.001)$ or with comorbidity $(\mathrm{aHR}=0.80,95 \% \mathrm{CI}=0.77$ to $0.83, \mathrm{p}<0.001)$, and those with follow-up period greater than 1 year.

Table 4 presents the incidence and $\mathrm{HR}$ of $\mathrm{AD} / \mathrm{AN}$ for the GD cohort with cholecystectomy was lower than that for the GD cohort without cholecystectomy in each stratification of age, gender, the presence or absence of a comorbidity and those follow-up period <1 year, follow-up period 1-3 years and follow-up period $>3$ years. We conducted the competing risk analysis for $\mathrm{AD} / \mathrm{AN}$ with death as a competing risk (table 5). The results were $1.00(95 \% \mathrm{CI}=0.92$ to 1.08$)$ in considering death as a competing risk.

\section{DISCUSSION}

Many epidemiological studies have supported the close association between GD and CVD, but the definition of CVD was limited to stroke and ischaemic heart disease in most of the literature. ${ }^{13-15}$ Although the pathophysiological mechanisms are quite similar for the development of CVD and $\mathrm{AD} / \mathrm{AN}$, to our knowledge our study is the first epidemiological study to assess the association between GD and the development of $\mathrm{AD} / \mathrm{AN}^{21-23}$ Along with our former studies regarding the association of GD with stroke, erectile dysfunction and migraine, this study may portend that GD is a predictor or an independent risk factor of systemic atherosclerosis. ${ }^{31-35}$ However, it requires more studies using other databases to confirm the association of GSD with atherosclerosis since our studies were conducted based on the same database (NHIRD).

In reviewing the literature (online supplemental table 1), there have been several epidemiological studies examining the effect of cholecystectomy on vascular diseases. ${ }^{31-33}$ 36-38 All our former studies from the same database supported the ameliorating effect of cholecystectomy on atherosclerotic diseases, including acute myocardial infarction (AMI), stroke, organic erectile erection, migraines. ${ }^{31-33} 36$ However, we noted that the risks of atherosclerosis between non-GD group and GD group with cholecystectomy were quite heterogeneous in our studies, including being comparable for erection dysfunction, being greater for AMI in GD with cholecystectomy, and being lower for $\mathrm{AD} / \mathrm{AN}$ in GD with cholecystectomy. One study from Mexico showed the deteriorating effect of cholecystectomy on the development of CVD, but the comparison group was general population without GD, rather than the GD subjects without cholecystectomy. ${ }^{37}$ Therefore, it deserves more studies from other database to clarify the effect of cholecystectomy on the prevention of atherosclerotic diseases and if the ameliorating effect can be supported in the laboratory studies.

We have tried several sensitivity analyses to validate our findings: (1) figure 1 shows the cumulative incidence of $\mathrm{AD} / \mathrm{AN}$ for the GD cohort without cholecystectomy was greater than that for the non-GD cohort even though the duration of follow-up was shorter in the GD cohort 


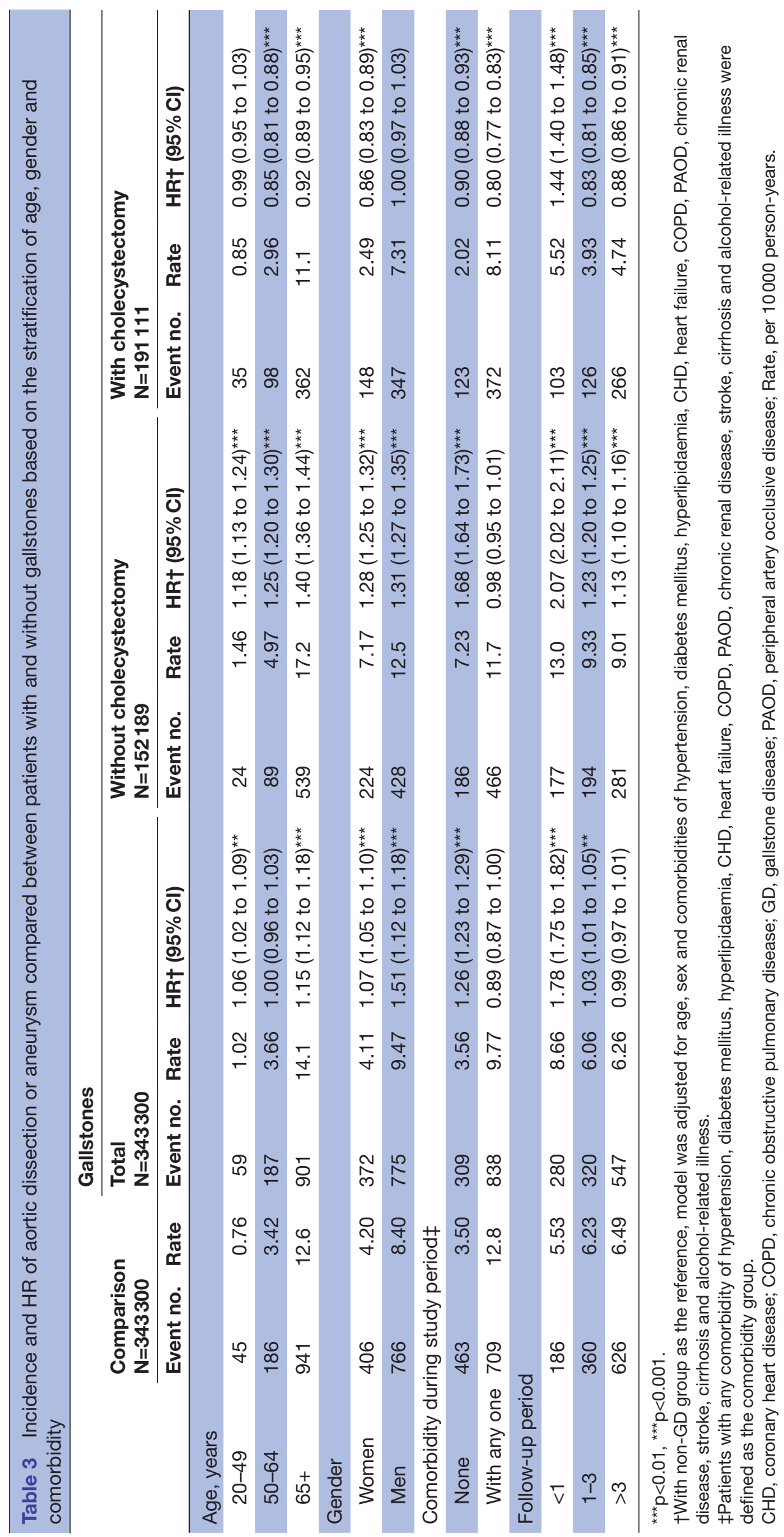


Table 4 Incidence and HR of aortic dissection or aneurysm compared between gallstones patients with and without cholecystectomy based on the stratification of age, gender and comorbidity

\begin{tabular}{|c|c|c|}
\hline & $\begin{array}{l}\text { Gallstones without } \\
\text { cholecystectomy } \\
\mathrm{N}=152189\end{array}$ & $\begin{array}{l}\text { Gallstones with } \\
\text { cholecystectomy } \\
\mathrm{N}=191111\end{array}$ \\
\hline & $\mathrm{HR}+(95 \% \mathrm{Cl})$ & $\mathrm{HR}+(95 \% \mathrm{Cl})$ \\
\hline \multicolumn{3}{|l|}{ Age, years } \\
\hline $20-49$ & 1.00 & $0.87(0.82 \text { to } 0.91)^{\star \star *}$ \\
\hline $50-64$ & 1.00 & $0.67(0.64 \text { to } 0.70)^{\star \star *}$ \\
\hline $65+$ & 1.00 & $0.66(0.64 \text { to } 0.69)^{\star \star \star}$ \\
\hline \multicolumn{3}{|l|}{ Gender } \\
\hline Women & 1.00 & $0.67(0.65 \text { to } 0.70)^{\star \star \star}$ \\
\hline Men & 1.00 & $0.77(0.75 \text { to } 0.80)^{\star \star \star}$ \\
\hline \multicolumn{3}{|l|}{ Comorbidity } \\
\hline None & 1.00 & $0.59(0.57 \text { to } 0.61)^{\star \star \star}$ \\
\hline With any one & 1.00 & $0.83(0.80 \text { to } 0.86)^{\star \star \star}$ \\
\hline \multicolumn{3}{|l|}{ Follow-up period } \\
\hline$<1$ & 1.00 & $0.69(0.67 \text { to } 0.71)^{\star \star \star}$ \\
\hline $1-3$ & 1.00 & $0.68(0.66 \text { to } 0.70)^{\star \star \star}$ \\
\hline$>3$ & 1.00 & $0.79(0.77 \text { to } 0.82)^{\star * \star}$ \\
\hline
\end{tabular}

${ }^{* * *} \mathrm{p}<0.001$.

†Model was adjusted for age, sex and comorbidities of hypertension, diabetes mellitus, hyperlipidaemia, CHD, heart failure, COPD, PAOD, chronic renal disease, stroke, cirrhosis and alcohol-related illness. .CHD, coronary heart disease; COPD, chronic obstructive pulmonary disease; PAOD, peripheral artery occlusive disease; Rate, per 10000 person-years.

without cholecystectomy; (2) table 3 show the risk of $\mathrm{AD} / \mathrm{AN}$ for the GD cohort without cholecystectomy was persistently greater than that for the non-GD cohort in each stratification of age group, sex, the absence of a comorbidity and the follow-up period; (3) figure 1 shows that the risk of $\mathrm{AD} / \mathrm{AN}$ for the GD cohort with cholecystectomy was lower than that for the non-GD cohort

Table 5 Subhazard ratios of aortic dissection or aneurysm and $95 \% \mathrm{Cls}$ compared between patients without gallstones and gallstones patients with or without cholecystectomy

\begin{tabular}{|c|c|c|}
\hline Variables & cSHR $(95 \% \mathrm{Cl})$ & aSHR $(95 \% \mathrm{Cl}) \dagger$ \\
\hline \multicolumn{3}{|l|}{ Gallstones } \\
\hline No & 1 (Reference) & 1 (Reference) \\
\hline Yes & 1.00 (0.93 to 1.09$)$ & $1.00(0.92$ to 1.08$)$ \\
\hline $\begin{array}{l}\text { Without } \\
\text { cholecystectomy }\end{array}$ & $1.36(1.23 \text { to } 1.49)^{\star \star \star}$ & $1.07(0.97$ to 1.18$)$ \\
\hline With cholecystectomy & $0.75(0.67 \text { to } 0.83)^{\star \star \star}$ & $0.91(0.82$ to 1.01$)$ \\
\hline
\end{tabular}

${ }^{* \star *} \mathrm{p}<0.001$

†Model was adjusted for age, sex and comorbidities of hypertension, diabetes mellitus, hyperlipidaemia, CHD, heart failure, COPD, PAOD, chronic renal disease, stroke, cirrhosis and alcohol-related illness. aSHR, adjusted subhazard ratio; CHD, coronary heart disease; COPD, chronic obstructive pulmonary disease; cSHR, crude subhazard ratio; PAOD, peripheral artery occlusive disease. even though the duration of follow-up was longer in the GD cohort without cholecystectomy; and (4) table 3 has shown that the risk of $\mathrm{AD} / \mathrm{AN}$ for the GD cohort with cholecystectomy was lower than that for the non-GD cohort without cholecystectomy in each stratification of age greater than 50 years, women, the presence or absence of a comorbidity, and greater than 1 year of follow-up period.

It remains uncertain about the pathophysiological mechanisms for the association of $\mathrm{AD} / \mathrm{AN}$ with GD and cholecystectomy. However, the following possible explanations have been suggested for the association of $\mathrm{AD} / \mathrm{AN}$ with GD. First, GD and $\mathrm{AD} / \mathrm{AN}$ share many common risk factors, such as ageing, sex, hypertension, diabetes and hyperlipidaemia. ${ }^{15}$ Second, increased cholesterol accumulation is common for GD with increased cholesterol secretion of bile and for $\mathrm{AD} / \mathrm{AN}$ with atherosclerosis. ${ }^{13-15}$ Moreover, common genetic linkage for abnormal biosynthesis, metabolism and transport can be observed in GD and atherosclerosis. ${ }^{19}$ Third, increased systemic oxidative stress or inflammation can be observed in patients with GD. Moreover, the inflammatory process can enhance atherosclerosis or atherothrombosis. ${ }^{17}$ Fourth, dysbiosis in the bowels and biliary tract promotes the development of GD by impairing the enterohepatic circulation of the bile. $^{183940}$

The following mechanisms may explain the protective effect of cholecystectomy against the development of $\mathrm{AD}$ / AN. First, increased oxidative stress and free radical reactions have been observed in patients with GD or cholecystitis, and these could be decreased after cholecystectomy. ${ }^{41}$ Second, dysbiosis can enhance gallstone formation due to imbalanced bile acid and cholesterol secretion in the bile. ${ }^{42}$ However, another study showed that changes in intestinal microbiota composition and diversity was seen after cholecystectomy, not in asymptomatic gallstones. ${ }^{43}$ Third, gallstones could be complicated with several bacterial microorganisms and often the indication for cholecystectomy is cholecystitis. ${ }^{44}$ Moreover, several of these bacteria have been associated with the development of $\mathrm{AD}$ or AN. ${ }^{45}$ Bacterial biofilm even has been supposed to be related to the formation of gallstones without symptoms and atherosclerosis. ${ }^{46}$ The bacteriology was not available in our database, but cholecystectomy might eliminate the source of bacterial colonisation.

The study has several merits. First, the findings of this study with a 12-year-long follow-up provides the generalisability in Taiwan because the NHI programme is a mandatory and single-payer healthcare system with a coverage of almost every resident in Taiwan (99.6\%). Second, the misclassification of asymptomatic gallstones into general population can be mitigated by comparing the risk of $\mathrm{AD}$ / AN between the gallstones patients with cholecystectomy and without cholecystectomy, rather than between cholecystectomy and general population. Third, this study also compares the survival and cumulative incidence of $\mathrm{AD}$ / AN by Kaplan-Meier method to avoid the detection bias due to temporal effect. 
The study has several limitations. First, this study is subject to the limited information on dietary habits and life styles even though we have replaced the diagnosis of smoking with COPD for smoking and alcohol drinking with alcohol-related illness, respectively. Second, we cannot individually validate the accuracy of each medical chart. The study is based on an NHI database, and a risk of selection bias (misclassification) or missing data could not be excluded. However, the Ministry of Health and Welfare in Taiwan has inspected the insurance claims for medical reimbursement, and it has been demonstrated a substantial concordance between the claims data in NHIRD and the patient self-reports. ${ }^{47} 48$ Third, the data from 2000 to 2010 seem quite dated. However, this large case-control cohort with 343300 population and 12-year-long follow-up has empowered the statistical significance and the accuracy of this database has been well recognised. ${ }^{47}{ }^{48}$ Fourth, the original NHRI database could not provide the mortality information. Although death would be the major reason for discontinuing the $\mathrm{NHI}$, the possible reasons for the discontinuity of NHI included death, withdrawal of insurance, immigration, etc. Therefore, the competing risk of death was overestimated and the protective effect of cholecystectomy on the development of $\mathrm{AD} / \mathrm{AN}$ would be underestimated in our study. Fifth, this observatory study cannot ascertain mechanism for the association of GD with $\mathrm{AD} / \mathrm{AN}$ and the protective mechanism of cholecystectomy against the development of $\mathrm{AD} / \mathrm{AN}$. Furthermore, we acknowledge that we could not exclude the possibility of lifestyle modification, such as dietary habits, exercise or weight reduction, with a resultant of decreased $\mathrm{AD} / \mathrm{AN}$ risk for the patients after cholecystectomy.

In conclusion, our findings demonstrate that the GD cohort was associated with a greater risk of $\mathrm{AD} / \mathrm{AN}$ than the non-GD cohort. Nevertheless, the risk of $\mathrm{AD} / \mathrm{AN}$ in the patients with GD would decrease after cholecystectomy. It needs more studies to ascertain the protective effect of cholecystectomy against the development of $\mathrm{AD} / \mathrm{AN}$ in patients with GD.

\section{Author affiliations}

${ }^{1}$ Digestive Disease Center, Changbing ShowChwan Memorial Hospital, Lukang Township, Taiwan

${ }^{2}$ College of Medicine, Chung-Hsing Univeristy, Taichung, Taiwan

${ }^{3}$ Department of Food Science and Technology, Hungkuang University, Taichung, Taiwan

${ }^{4}$ Management Office for Health Data, China Medical University Hospital, Taichung,

Taiwan

${ }^{5}$ College of Medicine, China Medical University, Taichung, Taiwan

${ }^{6}$ Graduate Institute of Biomedical Sciences, College of Medicine, China Medical University, Taichung, Taiwan

${ }^{7}$ Center of Augmented Intelligence in Healthcare, China Medical University Hospital, Taichung, Taiwan

${ }^{8}$ Nuclear Medicine and PET Center, China Medical University Hospital, Taichung, Taiwan

${ }^{9}$ Bioinformatics and Medical Engineering, Asia University, Taichung, Taiwan

Contributors Conceptualisation: C-HC, C-HK. Methodology: C-LL, C-HK. Software: C-LL, C-HK. Validation: C-HC, C-LL, C-HK. Formal analysis: C-HC, C-LL, C-HK. Investigation: C-LL, C-HK. Resources: C-LL, C-HK. Data curation: C-HC, C-LL, C-HK.
Writing (original draft preparation): C-HC, C-LL, C-HK. Writing (review and editing): C-HC, C-LL, C-HK. Visualisation: C-HC, C-LL, C-HK. Supervision: C-HK. Project administration: C-HK. Funding acquisition: C-HK.

Funding This study is supported in part by Taiwan Ministry of Health and Welfare Clinical Trial Center (MOHW109-TDU-B-212-114004), China Medical University Hospital (CMU107-ASIA-19, DMR-110-089); MOST Clinical Trial Consortium for Stroke (MOST 108-2321-B-039-003), Tseng-Lien Lin Foundation, Taichung, Taiwan. The funders and the enrolled participants had no role in the study design, data collection and analysis, the decision to publish or preparation of the manuscript. No additional external funding was received for this study.

Competing interests None declared.

Patient consent for publication Not required.

Ethics approval The National Health Research Institute (NHRI), a non-profit organisation for medical research and in charge of the administration of NHIRD, has encrypted the identifiable personal information into anonymous identification numbers of the relevant information in the NHIRD. The researchers could reach the database of NHIRD after approval by the NHRI without patient consent. In addition, the institutional review board (IRB) of China Medical University has approved this study (CMUH104-REC2-115-CR5).

Provenance and peer review Not commissioned; externally peer reviewed.

Data availability statement Data may be obtained from a third party and are not publicly available. The dataset used in this study is held by the Taiwan Ministry of Health and Welfare (MOHW), which has approved our application to access this data (Email: stcarolwu@mohw.gov.tw; Address: No.488, Sec. 6, Zhongxiao E. Rd., Nangang Dist., Taipei City 115, Taiwan (R.0.C.); Phone: +886-2-8590-6848).

Supplemental material This content has been supplied by the author(s). It has not been vetted by BMJ Publishing Group Limited (BMJ) and may not have been peer-reviewed. Any opinions or recommendations discussed are solely those of the author(s) and are not endorsed by BMJ. BMJ disclaims all liability and responsibility arising from any reliance placed on the content. Where the content includes any translated material, BMJ does not warrant the accuracy and reliability of the translations (including but not limited to local regulations, clinical guidelines, terminology, drug names and drug dosages), and is not responsible for any error and/or omissions arising from translation and adaptation or otherwise.

Open access This is an open access article distributed in accordance with the Creative Commons Attribution Non Commercial (CC BY-NC 4.0) license, which permits others to distribute, remix, adapt, build upon this work non-commercially, and license their derivative works on different terms, provided the original work is properly cited, appropriate credit is given, any changes made indicated, and the use is non-commercial. See: http://creativecommons.org/licenses/by-nc/4.0/.

ORCID iD

Chia-Hung Kao http://orcid.org/0000-0002-6368-3676

\section{REFERENCES}

1 Kuivaniemi H, Ryer EJ, Elmore JR, et al. Understanding the pathogenesis of abdominal aortic aneurysms. Expert Rev Cardiovasc Ther 2015;13:975-87.

2 Nienaber CA, Clough RE, Sakalihasan N, et al. Aortic dissection. Nat Rev Dis Primers 2016;2:1-17.

3 Adachi K, Iwasawa T, Ono T. Screening for abdominal aortic aneurysms during a basic medical checkup in residents of a Japanese rural community. Surg Today 2000;30:594-9.

4 Cheng SWK, Ting ACW, Tsang SHY. Epidemiology and outcome of aortic aneurysms in Hong Kong. World J Surg 2003;27:241-5.

5 Oh SH, Chang S-A, Jang SY, et al. Routine screening for abdominal aortic aneurysm during clinical transthoracic echocardiography in a Korean population. Echocardiography 2010;27:1182-7.

6 Lee SH, Chang S-A, Jang SY, et al. Screening for abdominal aortic aneurysm during transthoracic echocardiography in patients with significant coronary artery disease. Yonsei Med J 2015;56:38-44.

7 Wang S-W, Huang Y-B, Huang J-W, et al. Epidemiology, clinical features, and prescribing patterns of aortic aneurysm in Asian population from 2005 to 2011. Medicine 2015;94:e1716.

8 Yeh T-Y, Chen C-Y, Huang J-W, et al. Epidemiology and medication utilization pattern of aortic dissection in Taiwan. Medicine 2015;94:e1522.

9 Chen $\mathrm{CH}$, Huang $\mathrm{MH}$, Yang JC, et al. Prevalence and risk factors of gallstone disease in an adult population of Taiwan: an epidemiological survey. J Gastroenterol Hepatol 1743;2006:1737. 
10 Escarce JJ, Chen W, Schwartz JS. Falling cholecystectomy thresholds since the introduction of laparoscopic cholecystectomy. JAMA 1995;273:1581-5.

11 Ransohoff DF, Gracie WA, Wolfenson LB, et al. Prophylactic cholecystectomy or expectant management for silent gallstones. A decision analysis to assess survival. Ann Intern Med 1983;99:199-204.

12 Stinton LM, Myers RP, Shaffer EA. Epidemiology of gallstones. Gastroenterol Clin North Am 2010;39:157-69.

13 Fan LL, Chen BH, Dai ZJ. The relation between gallstone disease and cardiovascular disease. Sci Rep 2017;7:15104.

14 Upala S, Sanguankeo A, Jaruvongvanich V. Gallstone disease and the risk of cardiovascular disease: a systematic review and metaanalysis of observational studies. Scand J Surg 2017;106:21-7.

15 Zhao S-F, Wang A-M, Yu X-J, et al. Association between gallstone and cardio-cerebrovascular disease: systematic review and metaanalysis. Exp Ther Med 2019;17:3092-100.

16 Chen L-Y, Qiao QH, Zhang SC. Metabolic syndrome and gallstone disease. WJG 2012;18:4215-20.

17 Madamanchi NR, Vendrov A, Runge MS. Oxidative stress and vascular disease. Arterioscler Thromb Vasc Biol 2005;25:29-38.

18 Tang WHW, Kitai T, Hazen SL. Gut microbiota in cardiovascular health and disease. Circ Res 2017;120:1183-96.

19 Xue P, Niu W-Q, Jiang Z-Y, et al. A meta-analysis of apolipoprotein E gene $\varepsilon 2 / \varepsilon 3 / \varepsilon 4$ polymorphism for gallbladder stone disease. PLoS One 2012;7:e45849.

20 El-Lebedy D, Raslan HM, Mohammed AM. Apolipoprotein E gene polymorphism and risk of type 2 diabetes and cardiovascular disease. Cardiovasc Diabetol 2016;15:12.

21 Boddy AM, Lenk GM, Lillvis JH, et al. Bassic research studies to understand aneurysm disease. Drug News Perspect 2008;21:142-8.

22 Kuivaniemi H, Tromp G, Carey DJ. The molecular biology and genetics of aneurysms. In: Homeister JW, Willis MS, eds. Molecular and translational vascular medicine. New York: Springer Science + Business Media, 2012: 3-33.

23 Hernesniemi JA, Vänni V, Hakala T. The prevalence of abdominal aortic aneurysm is consistently high among patients with coronary artery disease. J Vasc Surg 2015;62:232-40.

24 Serin Halil İbrahim, Yilmaz YK, Turan Y, et al. The association between gallstone disease and plaque in the abdominopelvic arteries. J Res Med Sci 2017;22:11.

25 Chaikof EL, Dalman RL, Eskandari MK, et al. The society for vascular surgery practice guidelines on the care of patients with an abdominal aortic aneurysm. J Vasc Surg 2018;67:2-77.

26 Ouriel K, Ricotta JJ, Adams JT, et al. Management of cholelithiasis in patients with abdominal aortic aneurysm. Ann Surg 1983;198:717-9.

27 Universal Health Coverage in Taiwan. Bureau of national health insurance. Department of Health, Executive Yuan, 2012.

28 Database NHIR. Taiwan, 2015. Available: http://nhird.nhri.org.tw/en/ index.html

29 Frederick JR, Woo YJ. Thoracoabdominal aortic aneurysm. Ann Cardiothorac Sur 2012;1:277-85

30 Spencer SM, Trower AJ, Jia X, et al. Meta-analysis of the association between alcohol consumption and abdominal aortic aneurysm. $\mathrm{Br} J$ Surg 2017;104:1756-64.
31 Wei C-Y, Chuang S-H, Lin C-L, et al. Reduced risk of stroke following cholecystectomy: a nationwide population-based study. J Gastroenterol Hepatol 2019;34:1992-8.

32 Chen $\mathrm{C}-\mathrm{H}$, Lin C-L, Kao C-H. Erectile dysfunction in men with gallbladder stone disease: a nationwide population-based study. Am J Mens Health 2019;13:1557988319839589.

33 Chen C-H, Lin C-L, Kao C-H. Gallbladder stone disease is associated with an increased risk of migraines. J Clin Med 2018;7:455.

34 Yilmaz Avci A, Akkucuk MH, Torun E, et al. Migraine and subclinical atherosclerosis: endothelial dysfunction biomarkers and carotid intima-media thickness: a case-control study. Neurol Sci 2019;40:703-11.

35 van Os HJA, Mulder IA, Broersen A, et al. Migraine and cerebrovascular atherosclerosis in patients with ischemic stroke. Stroke 2017;48:1973-5.

36 Chen C-H, Lin C-L, Kao C-H. The effect of cholecystectomy on the risk of acute myocardial infarction in patients with gallbladder stones. Postgrad Med 2021;133:209-16.

37 Chavez-Tapia NC, Kinney-Novelo IM, Sifuentes-Rentería SE, et al. Association between cholecystectomy for gallstone disease and risk factors for cardiovascular disease. Ann Hepatol 2012;11:85-9.

38 Chen $\mathrm{C}-\mathrm{H}$, Lin $\mathrm{C}-\mathrm{L}$, Kao C-H. The risk of venous thromboembolism in patients with gallstones. Int $J$ Environ Res Public Health 2020;17:2930.

39 Cai J-S, Chen J-H. The mechanism of enterohepatic circulation in the formation of gallstone disease. J Membr Biol 2014:247:1067-82.

40 Wang Q, Jiao L, He C, et al. Alteration of gut microbiota in association with cholesterol gallstone formation in mice. BMC Gastroenterol 2017;17:74.

41 Sipos P, Krisztina J, Blazovics A, et al. Gallstones and free radical reactions in human gallbladder. Med Sci Monit 2001;7:84-8.

42 Wang $Q$, Hao C, Yao W, et al. Intestinal flora imbalance affects bile acid metabolism and is associated with gallstone formation. BMC Gastroenterol 2020;20:59.

43 Frost F, Kacprowski T, Rühlemann M, et al. Carrying asymptomatic gallstones is not associated with changes in intestinal microbiota composition and diversity but cholecystectomy with significant dysbiosis. Sci Rep 2021;11:6677.

44 Lee C-C, Chang I-J, Lai Y-C, et al. Epidemiology and prognostic determinants of patients with bacteremic cholecystitis or cholangitis. Am J Gastroenterol 2007;102:563-9.

45 Lin TW, Kan CD. Infected aortic aneurysm. aortic aneurysm. Rijeka, Croatia: InTech, 2017: 143-70.

46 Vestby LK, Grønseth T, Simm R, et al. Bacterial biofilm and its role in the pathogenesis of disease. Antibiotics 2020;9:59.

47 CS W, Lai MS, SSF G, et al. Concordance between patient selfreports and claims data on clinical diagnoses, medication use, and health system utilization in Taiwan. PLOS ONE 2014;9:e112257.

48 Cheng C-L, Lee C-H, Chen P-S, et al. Validation of acute myocardial infarction cases in the National Health Insurance Research Database in Taiwan. J Epidemiol 2014;24:500-7. 